Article

\title{
Phytochemicals and Antioxidant Activity of Korean Black Soybean (Glycine max L.) Landraces
}

\author{
Kyung Jun Lee ${ }^{1}{ }^{(\mathbb{D}}$, Da-Young Baek ${ }^{2}$, Gi-An Lee ${ }^{1}$, Gyu-Taek Cho ${ }^{1}$, Yoon-Sup So ${ }^{2}$, Jung-Ro Lee ${ }^{1}$, \\ Kyung-Ho Ma ${ }^{3}{ }^{-}$, Jong-Wook Chung ${ }^{4, *}$ and Do Yoon Hyun ${ }^{1, *}$ \\ 1 National Agrobiodiversity Center, National Institute of Agricultural Sciences (NAS), RDA, Jeonju 54874, \\ Korea; 1kj5214@korea.kr (K.J.L.); gknt11@korea.kr (G.A.-L.); gtcho@korea.kr (G.-T.C.); \\ jrmail@korea.kr (J.-R.L.) \\ 2 Department of Crop Science, Chungbuk National University, Chungdae-ro 1, Seowon-Gu, Cheongju, \\ Chungbuk 28644, Korea; dayung96@naver.com (D.-Y.B.); yoonsupso@chungbuk.ac.kr (Y.-S.S.) \\ 3 Department of Herbal Crop Research, NIHHS, RDA, Eumseong 27709, Korea; khma@korea.kr \\ 4 Department of Industrial Plant Science and Technology, Chungbuk National University, Chungdae-ro 1, \\ Seowon-Gu, Cheongju, Chungbuk 28644, Korea \\ * Correspondence: jwchung73@chungbuk.ac.kr (J.-W.C.); dyhyun@korea.kr (D.Y.H.); \\ Tel.: +82-43-261-2518 (J.-W.C.); +82-63-238-4912 (D.Y.H.)
}

Received: 30 January 2020; Accepted: 3 March 2020; Published: 5 March 2020

\begin{abstract}
Black soybean (Glycine max L.) has been used as a traditional medicine because its seed coat contains various natural phenolic compounds such as anthocyanins. The objective of this study was to reveal the genetic variation in the agricultural traits, phytochemicals, and antioxidant activity of 172 Korean black soybean landraces (KBSLs) and establish a relationship among them. The evaluation of three agricultural traits (days to $50 \%$ flowering, maturity, and 100 -seed weight), six phytochemicals (delphinidin-3-glucoside, cyaniding-3-glucoside, petunidin-3-glucoside, daidzin, glycitin, and genestin), and four antioxidant activities (2,2-diphenyl-1-picrylhydrazyl (DPPH), 2,2'-azino-bis-(3-ethylbenzothiazoline-6-sulfonic acid)(ABTS), ferric-reducing antioxidant power (FRAP), and the total polyphenol content (TPC) of 172 KBSLs were analyzed in 2012 and 2015. The agricultural traits, phytochemicals, and antioxidant activities of the 172 KBSLs showed wide variation among the accessions and years. In correlation analysis, the agricultural traits and phytochemicals showed positive and negative correlations with phytochemicals and antioxidant activity, respectively. The principal component analyses result indicated that phytochemicals accounted for most of the variability in the KBSLs. In clustering analysis, the 172 KBSLs were classified into four clusters. These results could lead to expanding the knowledge of the agricultural traits, phytochemicals, and antioxidant activity of the KBSLs, which are valuable materials for the development of new soybean varieties.
\end{abstract}

Keywords: antioxidant activity; black soybean; Glycine max; Korean landraces; phytochemicals

\section{Introduction}

Soybean (Glycine max L. Merr.) is widely cultivated and consumed throughout the world as grains, tofu, and soy milk [1]. It contains $40 \%$ protein and $20 \%$ lipid, which mainly consists of unsaturated fatty acids such as oleic acid and linoleic acid [2]. In addition, soybean has various compounds beneficial to health, such as isoflavone, oligosaccharide, saponins, and phenolics [3,4]. These reportedly have preventive effects on cancer, cardiovascular disease, obesity, and diabetes [1].

Soybean coat color is an important attribute determining the outward appearance of the soybean seed, which exists in a range of colors from yellow, green, brown, and black, to bicolored [5]. 
Among them, black soybean has been used in folk medicine in China, India, Japan, and Korea for hundreds of years [6]. Recently, black soybeans have been found to contain high contents of $\gamma$-tocopherol, isoflavones, flavonoids, and anthocyanins with biological activity [7]. Antioxidant properties resulting from the free-radical-scavenging activity and total phenolic compounds are higher in black soybeans compared to their yellow counterparts [8].

Phytochemicals are natural bioactive components that are abundant in foods such as whole-grain products, legumes, tea, and dark chocolate [9]. The most common phytochemicals in food include polyphenols, flavonoids, isoflavones, phenolic acids, stilbenoids, isothiocyanates, saponins, procyanidins, phenylpropanoids, anthraquinones, ginsenosides, and others [10,11]. In plants, the accumulation of phytochemicals is reportedly influenced by environmental factors and growth conditions. Alterations in the accumulation of phytochemicals in plants may have adverse effects on the health benefits resulting from their consumption [12].

There is increasing interest in natural antioxidant products as medicines and food additives [13,14]. More recently, antioxidant compounds have received attention from natural-product consumers and researchers due to their pharmacological properties. Antioxidants lower the oxidative stress caused by reactive oxygen species (ROS) [15]. Phytochemicals, such as polyphenols and carotenoids, are important because of their contributions to human health and multiple biological effects including antioxidant, antimutagenic, anticarcinogenic, and cytoprotective activities [16].

Korean soybean landraces have large genetic variations because Korea has a significantly long history of domestication and cultivation of soybean $[17,18]$. They have been used as genetic resources in the US, Canada, China, and Japan to develop elite cultivars with high yield, disease resistance, and tolerance to environmental stresses [19]. Landrace, defined by the Camacho-Villa et al., is "as dynamic populations of a cultivated plant with a historical origin and distinct identity, often genetically diverse and locally adapted, and associated with a set of farmers' practices of seed selection and field management, as well as with the farmers' knowledge base" [20]. Dwivedi et al. [21] referred to plant landraces as heterogeneous local adaptations of domesticated species providing genetic resources for farming in stressful environments. In addition, landraces show variable phenology, guarantee stable edible yield, and are often nutritionally superior.

In this study, the agricultural traits, phytochemicals, and antioxidant activities in a set of 172 Korean black soybean landraces (KBSLs) were evaluated. The aim of this study was to reveal the genetic variation in 172 KBSLs to provide information on KBSLs which are valuable as a functional food crop and/or a new dietary ingredient.

\section{Materials and Methods}

\subsection{Plant Materials and Agricultural Traits}

A total of 172 KBSLs were obtained from the National Agrobiodiversity Center of the Rural Development Administration (RDA), Republic of Korea. Each accession was sown with 20 seeds on May 25, 2012, at Suwon $(37.275015,126.984987)$ and on May 27, 2015, at Jeonju $(35.831037,127.062490)$. Standard RDA soybean management practices were applied for the cultivation. Days to $50 \%$ flowering (DF, about $50 \%$ of flowers open in all plants) and days to maturity (DM, approximately all pods are ripe; beans final color, dry and hard) of each KBSL were observed during cultivation, and 100-seed weight (SW) was measured after harvest. The harvested seeds were refrigerated at $-20{ }^{\circ} \mathrm{C}$ until they were retrieved for analyses.

\subsection{Phytochemical Analysis}

In order to analyze the anthocyanin content in each KBSL, the hand-peeled seed coats (100 mg) of $172 \mathrm{KBSL}$ were mixed with $15 \mathrm{~mL}$ of $1 \% \mathrm{HCl}$ in $99 \% \mathrm{MeOH}$ for $24 \mathrm{~h}$ at $4{ }^{\circ} \mathrm{C}$ in the dark. After centrifugation at $13000 \mathrm{rpm}$ for $10 \mathrm{~min}$, each specimen was filtered through a $0.45 \mu \mathrm{m}$ syringe filter and analyzed with an Agilent 1260 Infinity HPLC system (Agilent Technology, Santa Clara, CA, 
USA). The analysis was performed using a Waters XSelect HSS Cyano XP system $(2.5 \mu \mathrm{m}, 2.1 \times 75 \mathrm{~mm}$, Waters, Milford, MA, USA). The HPLC conditions were as follows: solvent A, 0.1\% TFA/H2O; solvent B, $0.1 \%$ TFA/CH3CN; gradient, $5 \%$ (B) for $0.3 \mathrm{~min}, 20 \%$ (B) for $6.0 \mathrm{~min}, 95 \%$ (B) for $8.0 \mathrm{~min}$, and $5 \%$ (B) for $10 \mathrm{~min}$; column temperature, $40{ }^{\circ} \mathrm{C}$; and flow rate, $0.5 \mathrm{~mL} / \mathrm{min}$. The filter detector was set at $520 \mathrm{~nm}$ (Supplemental Figure S1A).

To analyze the isoflavone content in each KBSL, $100 \mathrm{mg}$ of each sample (whole seeds) was added to $2 \mathrm{~mL}$ of $80 \% \mathrm{MeOH}$ and incubated with sonication for $1 \mathrm{~h}$. The sample in each tube was hydrolyzed using $150 \mu \mathrm{L}$ of $2 \mathrm{~N} \mathrm{NaOH}$. After mixing for $10 \mathrm{~min}$, the solutions were neutralized with $50 \mu \mathrm{l}$ of glacial acetic acid. The sample was centrifuged for $5 \mathrm{~min}$ at $3000 \mathrm{rpm}$, and the collected supernatant was then filtered using a $0.45 \mu \mathrm{m}$ syringe filter prior to analysis with an Agilent 1260 Infinity HPLC system (Agilent Technology). The analysis was performed using a Proshell 120 SB-C15 $(2.7 \mu \mathrm{m}, 2.1 \times 50 \mathrm{~mm}$, Agilent Technology). The HPLC conditions were as follows: solvent A, $0.1 \% \mathrm{TFA} / \mathrm{H} 2 \mathrm{O}$; solvent $\mathrm{B}$, $0.1 \% \mathrm{TFA} / \mathrm{CH} 3 \mathrm{CN}$; gradient, $10 \%$ (B) for $0.35 \mathrm{~min}, 10 \%-30 \%$ (B) in $3.96 \mathrm{~min}$, held at $30 \%$ (B) for $0.36 \mathrm{~min}$, and re-equilibrated at $10 \%$ (B) for $1.8 \mathrm{~min}$; column temperature, $30{ }^{\circ} \mathrm{C}$; and flow rate, $0.58 \mathrm{~mL} / \mathrm{min}$. The filter detector was set at $254 \mathrm{~nm}$ (Supplemental Figure S1B).

\subsection{Analysis of Antioxidant Activities}

To compare antioxidant activities in 172 KBSLs, 2,2-diphenyl-1-picrylhydrazyl (DPPH), 2,2'-azino-bis-(3-ethylbenzothiazoline-6-sulfonic acid) (ABTS), ferric-reducing antioxidant power (FRAP), and total polyphenol content (TPC) assays were performed using previous methods described by Lee et al. [22]. To analyze the antioxidant activities, $100 \mathrm{mg}$ of each KBSL powder (whole seed) was used. The absorbance at each assay was determined using a spectrophotometer (Epoch; Bio-Tek, Winooski, VT, USA).

\subsection{Data Analysis}

All the data collected from three replicate experiments were expressed as the mean \pm standard deviation. Duncan's multiple-range test and correlation analyses were used to determine the differences between the 172 KBSLs using SPSS Statistics 20 (SPSS Inc., Chicago, IL, USA). The DPPH results expressed as $\mathrm{IC}_{50}$ were converted to $1 / \mathrm{IC}_{50}$ before clustering analysis. Integration of the antioxidant capacity results derived from different chemical methods was used to calculate the relative antioxidant capacity index (RACI) [23]. Hierarchical clustering was performed using R statistical software [24]. PAST3 software was used for principal component analyses (PCA) [25].

\section{Results}

\subsection{Agricultural Traits of 172 KBSLs}

There were variations in the 172 KBSLs in days to $50 \%$ flowering (DF), days to maturity (DM), and 100-seed weight (SW) in 2012 and 2015 (Table 1 and Supplemental Table S1). The DF ranged from 49 to 79 days in 2012 and 56 to 70 days in 2015, with an average of 62.6 and 61.0 days, respectively. The DM ranged from 108 to 160 days in 2012 and 115 to 146 days in 2015, with an average of 139.5 and 138.2 days, respectively. The SW ranged from 10.3 to $40.0 \mathrm{~g}$ in 2012 and 9.7 to $54.8 \mathrm{~g}$ in 2015, with an average of 26.5 and $28.7 \mathrm{~g}$, respectively. Among the three agricultural traits, the DF and SW were significantly different between black soybean accessions $(p<0.001)$ and experimental years $(p<0.001)$, whereas the DM was only significantly different between the accessions $(p<0.001)$ (Table 2$)$. 
Table 1. Descriptive statistics of agricultural traits, phytochemicals, and antioxidant activity in 172 Korean black soybean landraces.

\begin{tabular}{|c|c|c|c|c|c|c|c|c|c|}
\hline & & Year & Min & Max & Mean & SD & Skewness & Kurtosis & $\mathrm{CV}(\%)$ \\
\hline \multirow{6}{*}{$\begin{array}{l}\text { Agricultural } \\
\text { Traits }\end{array}$} & \multirow{2}{*}{$\mathrm{DF}^{1}$ (day) } & 2012 & 49 & 79 & 62.6 & 6.6 & 0.029 & -0.409 & 10.6 \\
\hline & & 2015 & 56 & 70 & 61.0 & 3.2 & 0.687 & -0.476 & 5.2 \\
\hline & \multirow{2}{*}{ DM (day) } & 2012 & 108 & 160 & 139.5 & 10.4 & -0.559 & 0.153 & 7.4 \\
\hline & & 2015 & 115 & 146 & 138.2 & 8.5 & -1.000 & -0.169 & 6.1 \\
\hline & \multirow{2}{*}{ SW (g) } & 2012 & 10.3 & 40.0 & 26.5 & 8.1 & -0.260 & -0.580 & 30.5 \\
\hline & & 2015 & 9.7 & 54.8 & 28.7 & 8.5 & -0.338 & 0.316 & 29.7 \\
\hline \multirow{6}{*}{$\begin{array}{l}\text { Anthocyanin } \\
\text { (mg/100 g dried } \\
\text { seed coat) }\end{array}$} & \multirow{2}{*}{ D3G } & 2012 & 0 & 273.0 & 92.7 & 65.5 & 0.636 & -0.172 & 70.7 \\
\hline & & 2015 & 0 & 320.5 & 98.4 & 56.3 & 0.790 & 1.095 & 57.2 \\
\hline & \multirow{2}{*}{ C3G } & 2012 & 12.2 & 2042.7 & 509.4 & 378.8 & 1.140 & 1.259 & 74.4 \\
\hline & & 2015 & 51.9 & 1498.3 & 511.6 & 355.9 & 0.678 & -0.549 & 69.6 \\
\hline & \multirow{2}{*}{ Pt3G } & 2012 & 0.0 & 158.7 & 17.8 & 17.4 & 3.850 & 25.386 & 97.7 \\
\hline & & 2015 & 0.0 & 434.2 & 18.5 & 34.4 & 10.502 & 126.198 & 185.8 \\
\hline \multirow{6}{*}{$\begin{array}{c}\text { Isoflavone } \\
\text { (mg/100 g dried } \\
\text { seeds) }\end{array}$} & \multirow{2}{*}{ Daidzin } & 2012 & 14.1 & 108.7 & 48.2 & 18.5 & 0.526 & 0.066 & 38.4 \\
\hline & & 2015 & 4.6 & 81.0 & 25.3 & 13.6 & 1.618 & 4.280 & 53.5 \\
\hline & \multirow{2}{*}{ Glycitin } & 2012 & 0.8 & 43.2 & 14.7 & 8.6 & 0.839 & 0.635 & 58.2 \\
\hline & & 2015 & 0.4 & 19.9 & 3.8 & 2.8 & 2.078 & 7.158 & 72.1 \\
\hline & \multirow{2}{*}{ Genestin } & 2012 & 15.6 & 115.6 & 54.1 & 20.0 & 0.650 & 0.134 & 36.9 \\
\hline & & 2015 & 5.2 & 56.7 & 30.0 & 10.9 & 0.017 & -0.167 & 36.2 \\
\hline \multirow{8}{*}{$\begin{array}{l}\text { Antioxidant } \\
\text { activity }\end{array}$} & $\mathrm{DPPH}$ & 2012 & 63.2 & 311.1 & 108.0 & 45.3 & 1.514 & 2.705 & 42.0 \\
\hline & (IC 50) & 2015 & 16.4 & 154.6 & 59.5 & 29.7 & 0.940 & 0.588 & 49.8 \\
\hline & ABTS & 2012 & 1.1 & 7.0 & 5.0 & 1.2 & -0.600 & -0.183 & 23.7 \\
\hline & (mg AAE/g) & 2015 & 2.0 & 8.3 & 4.9 & 1.6 & 0.392 & -0.790 & 32.2 \\
\hline & TPC & 2012 & 2.8 & 13.0 & 7.1 & 2.3 & 0.425 & -0.426 & 32.0 \\
\hline & (mg GAE/g) & 2015 & 0.8 & 12.9 & 7.2 & 2.6 & -0.176 & -0.543 & 36.4 \\
\hline & FRAP & 2012 & 0.3 & 2.5 & 1.1 & 0.5 & 0.628 & 0.022 & 42.7 \\
\hline & (mg AAE/g) & 2015 & 0.3 & 3.1 & 1.1 & 0.6 & 1.106 & 0.589 & 56.2 \\
\hline
\end{tabular}

${ }^{1} \mathrm{DF}$, days to 50\% flowering; DM, days to maturity; SW, 100-seed weight; D3G, delphinidin-3-O-b-D-glucoside; C3G, cyanidin-3-O-b-D-glucoside; Pt3G, petunidin-3-O-b-D-glucoside; $\mathrm{mg}$ AAE/g, milligrams of ascorbic acid equivalents (AAE) per gram of dry weight sample; $\mathrm{mg} \mathrm{GAE} / \mathrm{g}$, milligrams of gallic acid equivalents (GAE) per gram of dry weight sample.

Table 2. Mean squares according to year, genotypes and year $\mathrm{x}$ genotype interactions.

\begin{tabular}{|c|c|c|c|c|}
\hline & & Year $(\mathrm{Y})$ & Genotype (G) & Interaction $(G \times Y)$ \\
\hline \multirow{3}{*}{ Agricultural Traits } & $\mathrm{DF}^{1}$ (day) & $13.1^{* * *}$ & $2.2 * * *$ & - \\
\hline & DM (day) & $3.3 \mathrm{~ns}$ & $2.9 * * *$ & - \\
\hline & SW (g) & $52.5^{* * *}$ & $16.2 * * *$ & - \\
\hline \multirow{3}{*}{ Anthocyanin } & D3G (mg/100 g) & $60.8^{* * *}$ & $89.1^{* * *}$ & $60.7^{* * *}$ \\
\hline & C3G (mg/100 g) & $0.6 \mathrm{~ns}$ & $269.9^{* * *}$ & $85.49^{* * *}$ \\
\hline & Pt3G (mg/100 g) & $23.8^{* * *}$ & $321.6^{* * *}$ & $235.1^{* * *}$ \\
\hline \multirow{3}{*}{ Isoflavone } & Daidzin (mg/100 g) & $26906^{* * *}$ & $198^{* * *}$ & $117.2^{* * *}$ \\
\hline & Glycitin (mg/100 g) & $47810^{* * *}$ & $220.3^{* * *}$ & $159.1^{* * *}$ \\
\hline & Genestin (mg/100 g) & $27837^{* * *}$ & $135.4^{* * *}$ & $152.7^{* * *}$ \\
\hline \multirow{4}{*}{$\begin{array}{c}\text { Antioxidant } \\
\text { activity }\end{array}$} & DPPH (IC 50) & $21647 * * *$ & $149.3^{* * *}$ & $151^{* * *}$ \\
\hline & ABTS (mg AAE/g) & $1.6 \mathrm{~ns}$ & $10.6^{* * *}$ & $3.9 * * *$ \\
\hline & TPC (mg GAE/g) & $7.93 * *$ & $112.4^{* * *}$ & $18.8^{* * *}$ \\
\hline & FRAP (mg AAE/g) & $60.32 * * *$ & $322.2 * * *$ & $218.4^{* * *}$ \\
\hline
\end{tabular}

${ }^{1}$ DF, days to $50 \%$ flowering; DM, days to maturity; SW, 100-seed weight; D3G, delphinidin-3-O-b-D-glucoside; C3G, cyanidin-3-O-b-D-glucoside; Pt3G, petunidin-3-O-b-D-glucoside; mg AAE/g, milligrams of ascorbic acid equivalents (AAE) per gram of dry weight sample; mg GAE/g, milligrams of gallic acid equivalents (GAE) per gram of dry weight sample; ns, not significant; ${ }^{* *}, p<0.01 ;{ }^{* * *}, p<0.001$. 


\subsection{Content of Phytochemicals in 172 KBSLs}

The content of three anthocyanins (delphinidin-3-O-b-D-glucoside (D3G), cyanidin-3-O-b-D-glucoside (C3G), and petunidin-3-O-b-D-glucoside (Pt3G)) and isoflavone aglycones (daidzin, glycitin, and genestin) was measured in the $172 \mathrm{KBSLs}$ (Table 1 and Supplemental Table S1). Among anthocyanins, the D3G, C3G, and Pt3G contents were 0.0 to 273.0, 12.2 to 2042.7, and 0.0 to $158.7 \mathrm{mg} / 100 \mathrm{~g}$ dried seed coat, respectively, in 2012 and 9.1 to 320.5, 51.9 to 1498.3 , and 1.2 to $434.2 \mathrm{mg} / 100 \mathrm{~g}$ dried seeds, respectively, in 2015,. Among the anthocyanins, D3G and Pt3G showed significant differences between black soybean accessions $(p<0.001)$, the experimental years $(p$ $<0.001)$, and the interaction between year and accessions $(p<0.001)$, whereas the C3G content was different between black soybean accessions $(p<0.001)$ and the interaction between year and accessions $(p<0.001)$ (Table 2).

In the three isoflavone aglycones, the contents of daidzin, glycitin, and genestin were 14.1 to 108.7, 0.8 to 43.2 , and 15.6 to $115.6 \mathrm{mg} / 100 \mathrm{~g}$ dried seeds in 2012 and 4.6 to 81.0, 0.4 to 19.9, and 5.2 to $56.7 \mathrm{mg} / 100 \mathrm{~g}$ dried seeds in 2015 , respectively. The three isoflavone contents were significantly different between the black soybean accessions $(p<0.001)$, experimental years $(p<0.001)$, and the interaction between year and accessions $(p<0.001)$.

\subsection{Antioxidant Activities of 172 KBSLs}

The DPPH radical-scavenging activity ranged from 63.7 to $311.1\left(\mathrm{IC}_{50}\right)$ in 2012 and 16.4 to 154.6 $\left(\mathrm{IC}_{50}\right)$ in 2015 , with average values of 90.3 and 59.5 ( $\left(\mathrm{IC}_{50}\right)$, respectively, among the accessions evaluated (Table 1 and Supplemental Table S1). The ABTS antioxidant activities of the 172 Korean black soybean accessions were 1.1 to $7.0 \mathrm{mg}$ ascorbic acid equivalents (AAE)/g dried seeds in 2012 and 2.0 to $8.3 \mathrm{mg}$ AAE/g dried seeds in 2015. The TPC ranged from 2.8 to $13.0 \mathrm{mg}$ gallic acid equivalents (GAE)/g dried seeds in 2012 and 0.8 to $12.9 \mathrm{mg} \mathrm{GAE} / \mathrm{g}$ dried seeds in 2015 with an average of 7.1 and $7.2 \mathrm{mg}$ GAE/g, respectively. The FRAP assay revealed levels ranging from 0.3 to $2.5 \mathrm{mg} \mathrm{AAE} / \mathrm{g}$ in 2012 and 0.3 to $3.1 \mathrm{mg} \mathrm{AAE} / \mathrm{g}$ dried seeds, respectively. The DPPH, TPC, and FRAP were significantly different between the accessions (DPPH and FRAP, $p<0.001$; TPC, $p<0.01)$, experimental years $(p<0.001)$, and the interactions between years and accessions $(p<0.01)$, respectively, whereas the ABTS activity was significantly different between black soybean accessions $(p<0.01)$ and the interaction between year and accessions $(p<0.01)$. In the results of RACI, IT178047 was the highest $(2.21)$, followed by IT274457 (1.64), IT178132 (1.52), and IT177807 with the lowest value (-1.49) (Figure 1 and Supplemental Table S1).

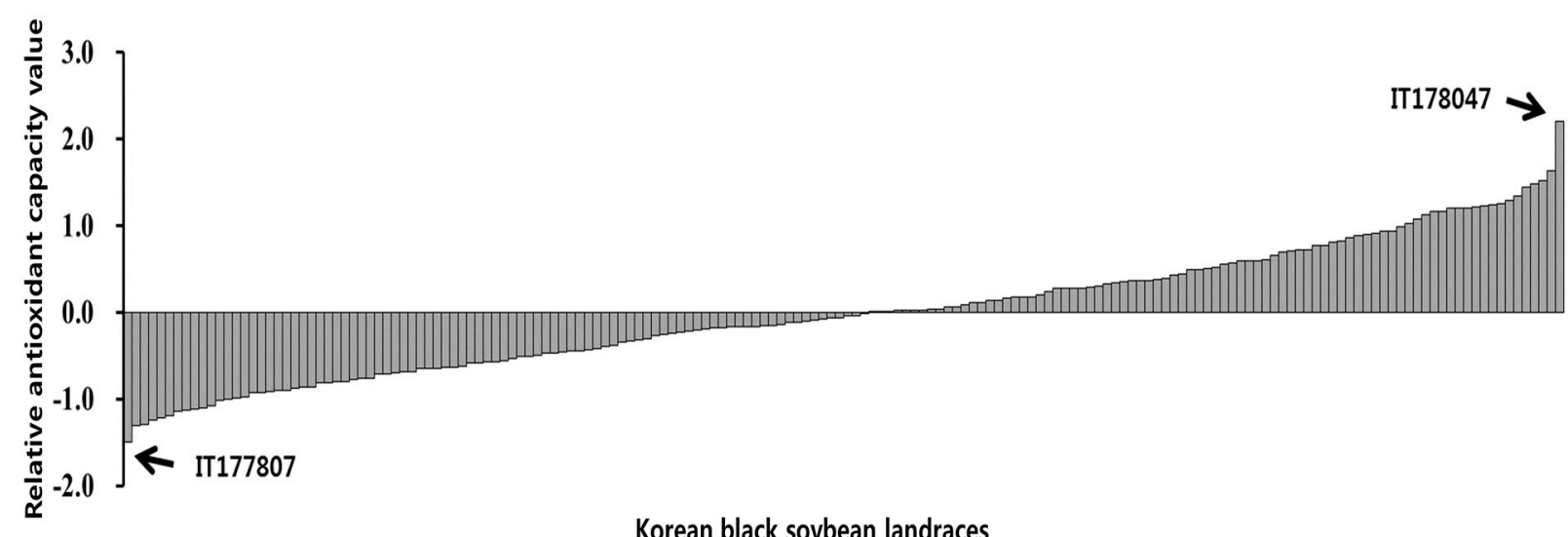

\section{Korean black soybean landraces}

Figure 1. Relative antioxidant capacity index of 172 Korean black soybean landraces.

\subsection{Correlations between Six Phytochemicals in 172 Korean Black Soybean Landraces}

The correlations between agricultural traits, phytochemicals, and antioxidant activities are shown in Table 3. There were positive correlations between anthocyanins (D3G and C3G, r $=0.461(p<0.001$ ); 
D3G and Pt3G, $\mathrm{r}=0.267$ ( $p<0.001)$; C3G and Pt3G, $\mathrm{r}=0.287(p<00.01)$ ) and isoflavones (daidzin and glycitin, $\mathrm{r}=0.651$ ( $p<0.001)$; daidzin and genestin, $\mathrm{r}=0.554(p<0.001)$; glycitin and genestin, $\mathrm{r}=0.362(p<0.0001))$. Between the anthocyanins and antioxidants, C3G showed correlations with DPPH ( $\mathrm{r}=-0.194, p<0.05)$, ABTS ( $\mathrm{r}=0.307, p<0.001)$, TPC $(\mathrm{r}=0.358, p<0.001)$, and FRAP $(\mathrm{r}=0.381$, $p<0.001)$. D3G showed correlations with DPPH $(\mathrm{r}=-0.293, p<0.001)$, ABTS $(\mathrm{r}=0.199, p<0.01)$, and FRAP $(r=0.199, p<0.01)$, whereas Pt3G was not corrected with antioxidant activities. Among the isoflavones, only genestin showed a positive correlation with ABTS activities $(\mathrm{r}=0.154, p<0.05)$. Among the agricultural traits, the DF and DM showed correlations with anthocyanins, isoflavones, and antioxidant activity, whereas the SW was only correlated with isoflavones.

Table 3. Correlations between agricultural traits, anthocyanins, isoflavones, and antioxidant activities in 172 Korea black soybean landraces.

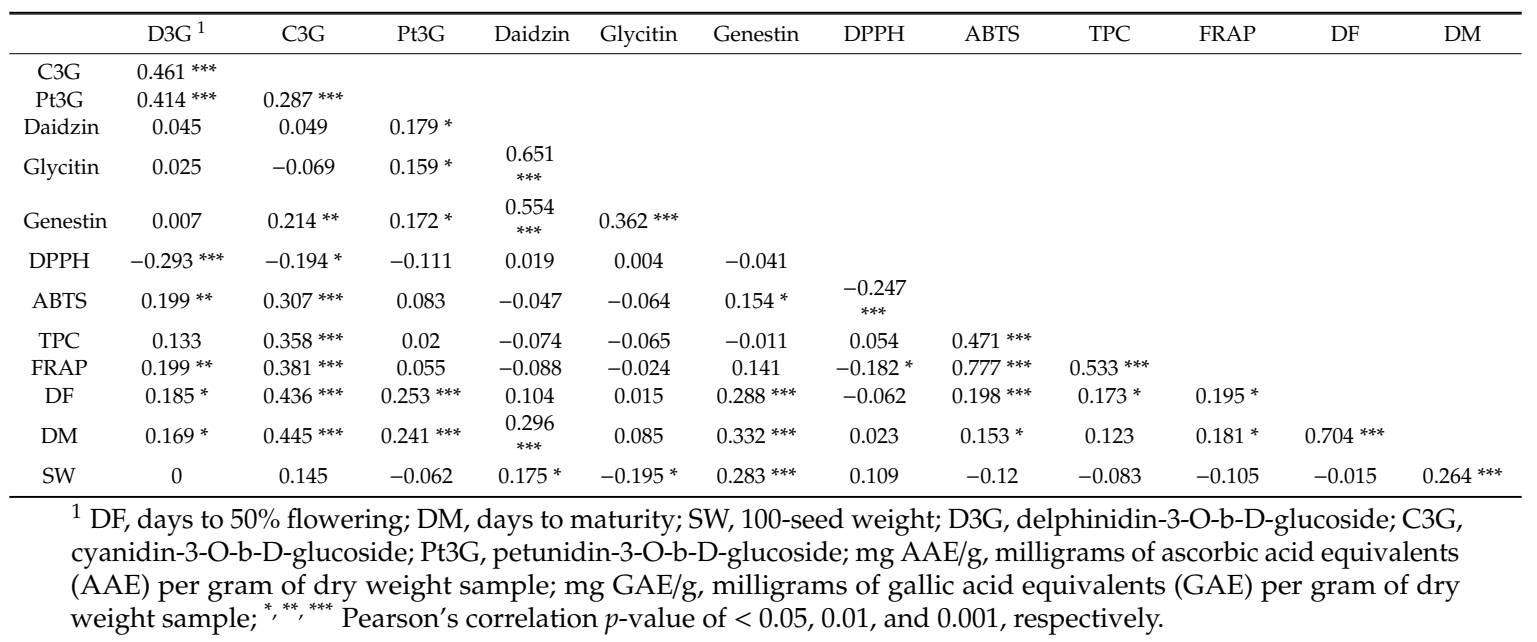

\subsection{PCA Analysis}

PCA using the agricultural traits, phytochemicals, and antioxidant activities of 172 KBSLs indicated that five principal components (PCs) with eigenvalues $>1$ could explain $73.94 \%$ of the total variance (Table 4). The first PC, with an eigenvalue of 1.8138, explained $25.3 \%$ of the total variance. C3G was the variable with the largest positive loading. The second PC, with an eigenvalue of 1.526, explained an additional $17.9 \%$ of the total variance. Isoflavone was the variable with the largest negative loading. The third PC, with an eigenvalue of 1.235 , explained an additional $11.7 \%$ of the total variance. Glycitin had the highest positive variance, and the SW had the highest negative variance. The fourth PC, with an eigenvalue of 1.187, explained an additional 10.8\%. D3G had the highest positive variance. The fifth PC, with an eigenvalue of 1.028 , explained an additional $8.0 \%$.

The first two PCs are plotted in Figure 2. By placing an ellipse around the data representing the 95\% confidence interval using Hoteling's T2 statistic, it was possible to observe all KBSL, except for three landraces. Among the three landraces, IT177771 and IT178047 showed the highest Pt3G and daidzin content and D3G, C3G, ABTS, TPC, and FRAP, respectively, whereas IT177910 showed lower anthocyanin (D3G was not detected), isoflavone, and antioxidant activities. 
Table 4. Principal component analysis of the phytochemicals and antioxidant activities of 172 Korea black soybean landraces, eigenvalues, and percentage variability explained by the first five components.

\begin{tabular}{cccccc}
\hline Parameter & PC1 & PC2 & PC3 & PC4 & PC5 \\
\hline Eigenvalue & 1.813 & 1.526 & 1.235 & 1.187 & 1.028 \\
\% variance & $25.3 \%$ & $17.9 \%$ & $11.7 \%$ & $10.8 \%$ & $8.1 \%$ \\
Cumulative variability & $25.3 \%$ & $43.2 \%$ & $54.9 \%$ & $65.8 \%$ & $73.9 \%$ \\
D3G ${ }^{1}$ & 0.281 & 0.069 & 0.110 & 0.507 & -0.116 \\
C3G & 0.411 & 0.063 & -0.186 & 0.167 & -0.068 \\
Pt3G & 0.248 & -0.127 & 0.145 & 0.453 & 0.167 \\
Daidzin & 0.151 & -0.507 & 0.248 & -0.167 & -0.094 \\
Glycitin & 0.080 & -0.393 & 0.502 & -0.151 & 0.190 \\
Genestin & 0.253 & -0.382 & 0.063 & -0.236 & -0.293 \\
DPPH & 0.134 & 0.150 & 0.353 & 0.342 & -0.417 \\
ABTS & 0.346 & 0.310 & 0.189 & -0.272 & -0.157 \\
TPC & 0.270 & 0.286 & -0.013 & -0.336 & 0.170 \\
FRAP & 0.354 & 0.329 & 0.151 & -0.304 & -0.096 \\
DF & 0.359 & -0.107 & -0.278 & 0.066 & 0.402 \\
DM & 0.361 & -0.229 & -0.354 & -0.004 & 0.199 \\
SW & 0.041 & -0.212 & -0.479 & -0.064 & -0.621 \\
\hline
\end{tabular}

${ }^{1} \mathrm{DF}$, days to $50 \%$ flowering; DM, days to maturity; SW, 100-seed weight; D3G, delphinidin-3-O-b-D-glucoside; C3G, cyanidin-3-O-b-D-glucoside; Pt3G, petunidin-3-O-b-D-glucoside; mg AAE/g, milligrams of ascorbic acid equivalents (AAE) per gram of dry weight sample; mg GAE/g, milligrams of gallic acid equivalents (GAE) per gram of dry weight sample.

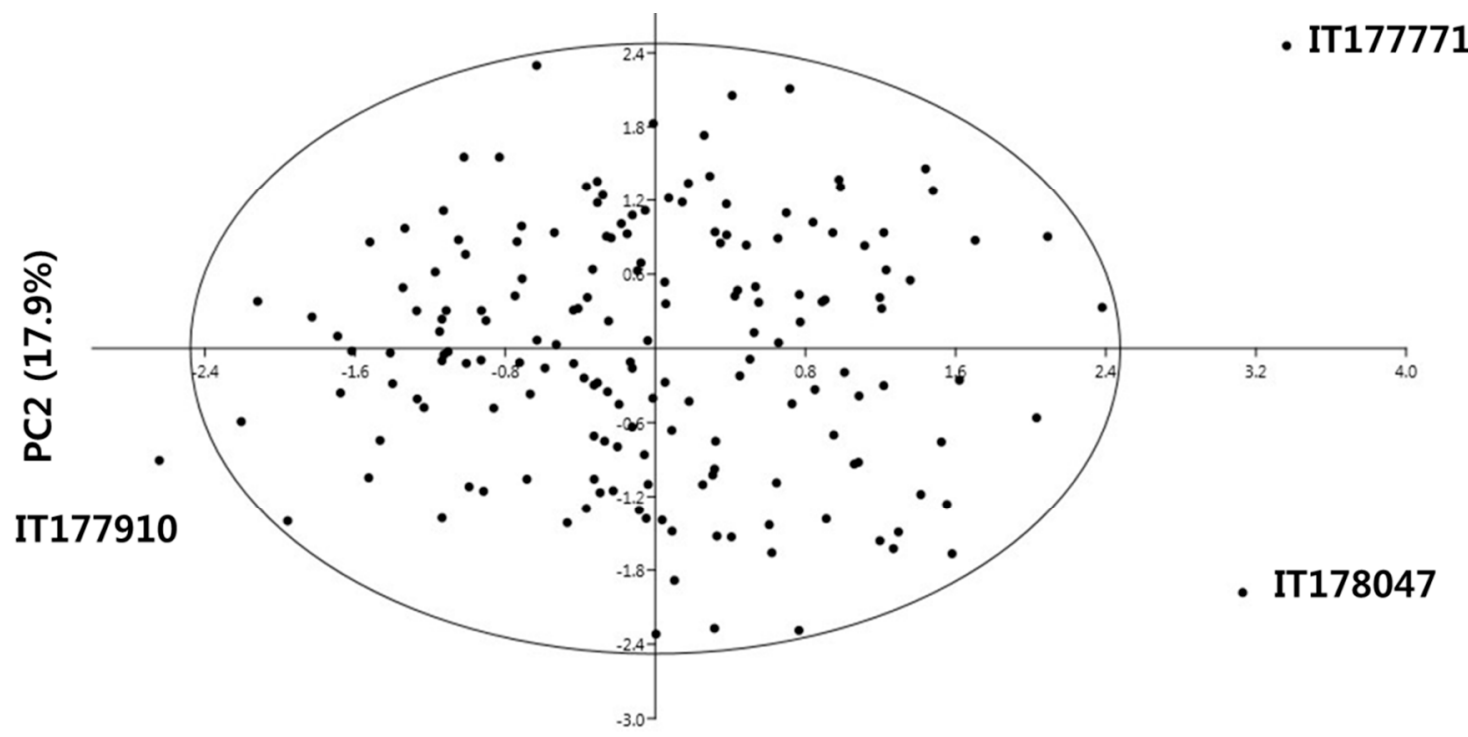

PC1 (25.3\%)

Figure 2. 2D scatter diagram of principal component analysis (PCA) of 172 KBSLs based on agricultural traits, phytochemicals, and antioxidant activities.

\subsection{Clustering Analysis}

The 172 KBSL were classified into four clusters according to their agricultural traits, phytochemicals, and antioxidant activities (Table 5 and Figure 3). Cluster I contained 47 KBSLs and had high isoflavone contents and the long DMs compared to the other clusters. Cluster II had 42 KBSLs and showed high anthocyanin contents, high antioxidant activities, long DFs and DMs, and high SWs. Cluster III consisted of 48 KBSLs and showed the lowest isoflavone content, high antioxidant activities, and lowest SWs. Cluster IV had 35 KBSLs with the lowest anthocyanin content and antioxidant activities. 
Table 5. Average cluster values of agricultural traits, phytochemicals, and antioxidant activities of 172 Korea black soybean landraces.

\begin{tabular}{|c|c|c|c|c|c|c|c|}
\hline Group & No. acc. & $\begin{array}{c}\text { D3G }^{1} \\
(\mathrm{mg} / 100 \mathrm{~g})\end{array}$ & $\begin{array}{c}\text { C3G } \\
(\mathrm{mg} / 100 \mathrm{~g})\end{array}$ & $\begin{array}{c}\text { Pt3G } \\
(\mathrm{mg} / 100 \mathrm{~g})\end{array}$ & $\begin{array}{c}\text { Daidzin } \\
(\mathrm{mg} / \mathbf{1 0 0} \mathrm{g})\end{array}$ & $\begin{array}{c}\text { Glycitin } \\
\text { (mg/100 g) }\end{array}$ & $\begin{array}{c}\text { Genestin } \\
(\mathrm{mg} / 100 \mathrm{~g})\end{array}$ \\
\hline 1 & 47 & $97.7 \mathrm{a}^{2}$ & $514 b$ & $22.7 \mathrm{a}$ & $51.0 \mathrm{a}$ & $13.7 \mathrm{a}$ & $47.4 \mathrm{a}$ \\
\hline 2 & 42 & $107.6 a$ & $816.2 a$ & $21.6 a$ & $33.6 \mathrm{~b}$ & $6.7 \mathrm{c}$ & $48.2 \mathrm{a}$ \\
\hline 3 & 48 & $104.6 a$ & $440.7 \mathrm{~b}$ & $17.2 \mathrm{ab}$ & $28.2 \mathrm{c}$ & 7.1c & $35.9 b$ \\
\hline \multirow[t]{2}{*}{4} & 35 & $65.7 \mathrm{~b}$ & $234.6 \mathrm{c}$ & $9.2 b$ & $33.1 b$ & $9.3 b$ & $36.1 b$ \\
\hline & $\begin{array}{l}\mathrm{DPPH} \\
\left(\mathrm{IC}_{50}\right)\end{array}$ & $\begin{array}{c}\text { ABTS (mg } \\
\text { AAE/g) }\end{array}$ & $\begin{array}{l}\text { TPC (mg } \\
\text { GAE/g) }\end{array}$ & $\begin{array}{c}\text { FRAP (mg } \\
\text { AAE/g) }\end{array}$ & DF (day) & DM (day) & SW (g) \\
\hline 1 & $80.2 b$ & $4.7 \mathrm{~b}$ & $6.9 b$ & $0.9 \mathrm{c}$ & $63.4 \mathrm{~b}$ & $142.8 \mathrm{a}$ & $26.8 b$ \\
\hline 2 & $77.9 \mathrm{~b}$ & $5.5 \mathrm{a}$ & $8.0 \mathrm{a}$ & $1.4 \mathrm{a}$ & $65.0 \mathrm{a}$ & $145.1 \mathrm{a}$ & $33.5 a$ \\
\hline 3 & $67.6 a$ & $5.4 \mathrm{a}$ & 7.4ab & $1.2 \mathrm{~b}$ & $61.2 \mathrm{c}$ & $135.9 \mathrm{~b}$ & $22.9 c$ \\
\hline 4 & $80.2 b$ & $4.1 \mathrm{c}$ & $6.1 \mathrm{c}$ & $0.8 \mathrm{c}$ & $56.6 \mathrm{~d}$ & $130.1 \mathrm{c}$ & $28.0 \mathrm{~b}$ \\
\hline
\end{tabular}

${ }^{1} \mathrm{DF}$, days to $50 \%$ flowering; $\mathrm{DM}$, days to maturity; SW, 100-seed weight; D3G, delphinidin-3-O-b-D-glucoside; C3G, cyanidin-3-O-b-D-glucoside; Pt3G, petunidin-3-O-b-D-glucoside; mg AAE/g, milligrams of ascorbic acid equivalents (AAE) per gram of dry weight sample; $\mathrm{mg} \mathrm{GAE} / \mathrm{g}$, milligrams of gallic acid equivalents (GAE) per gram of dry weight sample. ${ }^{2}$ The same letter in each column indicates no significant difference by Duncan's multiple range test, $p<0.05$.

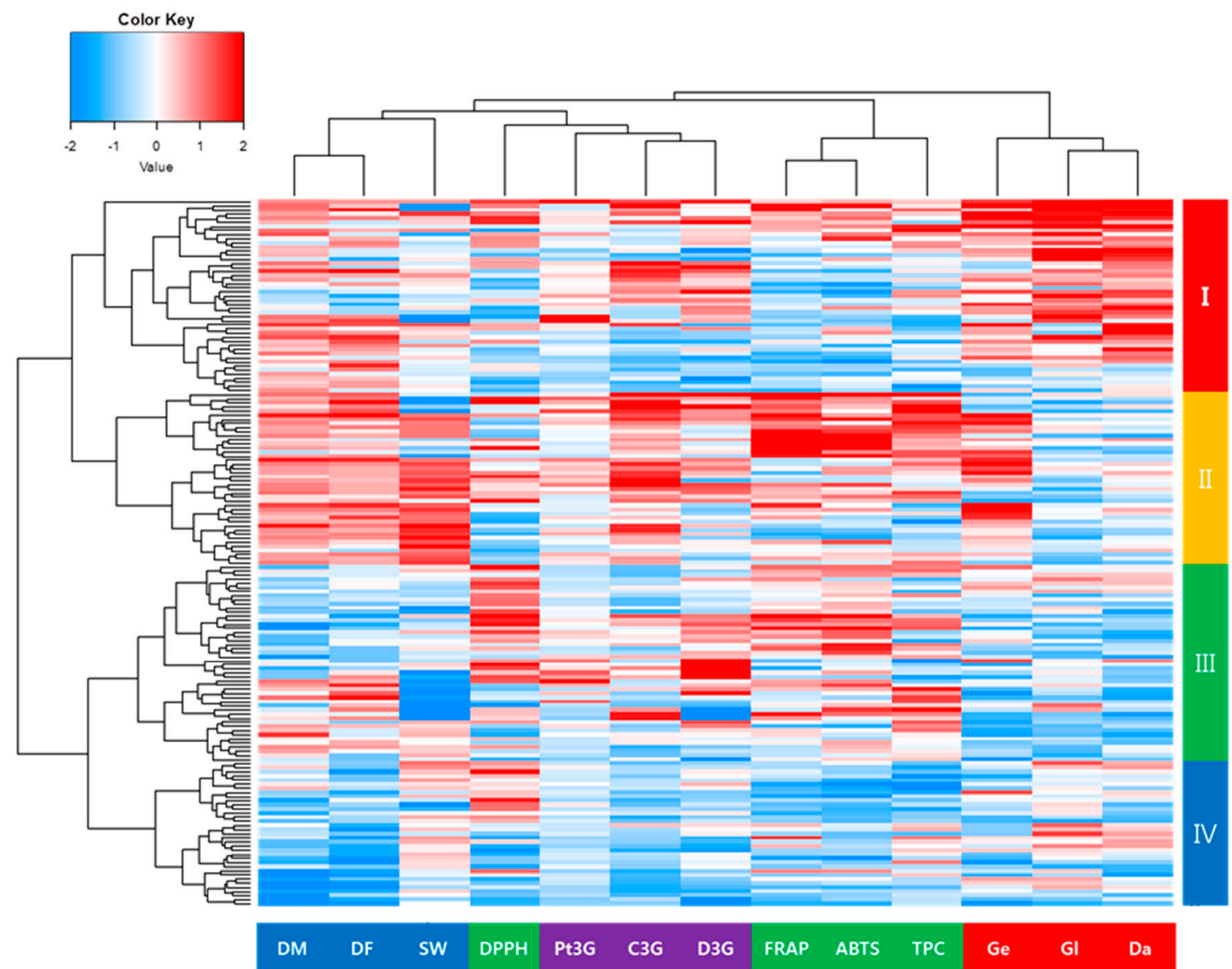

Figure 3. Hierarchical clustering analysis of agricultural traits, phytochemicals, and antioxidant activities in 172 Korean black soybean landraces.

\section{Discussion}

In this study, the agricultural traits, phytochemicals, and antioxidant activity of 172 KBSLs were evaluated to identify their potential as new breeding materials. The results showed that the 172 KBSLs 
had wide variations in agricultural traits, phytochemicals, and antioxidant activity. Hoisington et al. [26] suggested that the success of a breeding program depends on the genetic variability available to the breeders. In addition, Sthapit et al. [27] suggested that landraces could be effectively improved by simple trait selection if the landraces could offer sufficient natural variation in the population. The landrace contained important genetic variability, which determines their ability to adapt to changes in their environment and provides an important source of useful variability for breeding activities, provided that they are accompanied by information on characterization and agronomic evaluation $[28,29]$. Thus, the results of this study could be used as the basis for enhancing the availability of KBSLs.

Many methods measuring antioxidant activity have been developed and used to determine the antioxidant capacity of plant extracts because they use relatively standard equipment and can deliver fast and reproducible results [30]. In this study, the free-radical-scavenging capacity of 172 KBSLs using the DPPH, ABTS, TPC, and FRAP assays was determined. Each method showed different grades depending on the soybean accessions and the year. Sun and Tanumihardjo [23] reported that each method of measuring antioxidant activity had its own limitations because various reaction mechanisms and different phase locations can affect the measurements. Therefore, Sun and Tanumihardjo [23] suggested using RACI. They described the advantage of RACI, which is a numerical scale that can integrate multiple chemical methods, thus allowing the comparison of the antioxidant capacity in a large number of samples. To compare data obtained by different chemical methods used to evaluate antioxidant activity, the RACI in the KBSLs was used in this study. The results of the RACI can be used to select KBSLs with high antioxidant activity so that new breeding materials can be confirmed.

The DF was positively correlated with anthocyanins, genestin, and antioxidant activities. Phommalath et al. [31] reported similar results, that flowering date showed significant positive correlations with TPC, total flavonoid content, and radical scavenging activity. They demonstrated that the reasons for the relationship between flowering dates and phenolic contents were due to the effect of temperature during maturation. Soybean accessions from high latitudes generally flower earlier than those from low latitudes because they are exposed to high temperatures during maturation. Tsukamoto et al. [32] reported that soybean seeds grown at high-temperature conditions had lower isoflavone contents than those grown at lower temperatures. Yaman et al. [33] and Cohen et al. [34] reported that higher temperatures inhibited the expression of flavonoid pathway genes, resulting in lower phenolic accumulation. The results of the present study may be attributed to similar mechanisms. In general, the monthly temperature in Korea is the highest in July and August. In fact, the average temperature in 2012 and 2015 was 24.4 and $26.4{ }^{\circ} \mathrm{C}$ in July, 25.2 and $25.4{ }^{\circ} \mathrm{C}$ in August, and 20.5 and $20.6^{\circ} \mathrm{C}$ in September [35]. In this study, the DF in 2012 and 2015 was distributed between July 13 to August 12 and July 22 to August 5, and it is expected that the KBSL with an early DF might be exposed to higher temperatures during the maturation period. However, more research on the relationships between phenolic compounds and temperatures during maturation is needed.

The black soybeans exhibited high levels of antioxidant activity because of their high concentrations of phenolic compounds [36]. In addition, the phenolic compounds were affected by genotype and environment, as well as the interaction between genotype and environment [31,37]. In this study, there was a difference in antioxidant activities between the KBSLs and the years. It seemed that the difference in the antioxidant activities was due to differences in the polyphenolic contents. [38] reported that various antioxidants showed substantially varying antioxidant effectiveness in different systems due to different molecular structures. Due to difficulties in measuring each antioxidant component separately, and interactions between these different antioxidant components in the network, several methods have been developed to assess the total antioxidant capacity of all the nonenzymatic antioxidant components [39]. In this study, the DPPH, ABTS, and FRAP activities were positively associated with D3G and C3G, whereas isoflavone was not correlated with antioxidant activities (Table 3). The black pigmentation of black soybeans is due to the accumulation of anthocyanins in the epidermal palisade layer of the seed coat [40]. Anthocyanins in the seed coats play an important role in the protection 
against oxidative damage [41]. Among them, C3G, which was the most abundant anthocyanin found in black soybeans, exhibited strong antioxidant activity among the three anthocyanins isolated from black beans [42]. Lee et al. [43] reported that the black seed coats had significantly higher total phenolic and total anthocyanin contents and antioxidant activity compared to whole beans and dehulled beans

Genetic variability is important to the success of a breeding program [44]. Therefore, the collection and preservation of germplasm are important because it provides raw materials for plant breeding and crop improvement [45]. However, germplasm-only collections, without evaluation of their characteristics, are difficult to use by breeders who have different interests and possibly different requirements [46]. Whereas breeders focus on characteristics with perceived immediate value, other biologists may be more interested in potential variation or use the collections to better understand the properties and behavior of the plants [45]. In this study, 172 KBSLs were evaluated, which showed significant differences in agricultural traits, phytochemicals, and antioxidant activities. In particular, 42 KSBLs contained within cluster II had higher levels of phytochemicals and antioxidant activities compared to the other landraces. The results of this study could contribute to the more efficient conservation and utilization of KBSLs to broaden the genetic bases of commercially grown varieties of soybean.

Supplementary Materials: The following are available online at http://www.mdpi.com/2076-3921/9/3/213/s1, Table S1. Agricultural traits, phytochemicals, and antioxidant activities of 172 Korean black soybean landraces. Supplemental Figure S1. HPLC chromatogram of anthocyanins (A) and isoflavones (B). D3G, delphinidin-3-O-b-D-glucoside; C3G, cyanidin-3-O-b-D-glucoside; Pt3G, petunidin-3-O-b-D-glucoside

Author Contributions: Conceptualization, K.J.L. and J.-W.C.; data curation, K.J.L.; formal analysis, K.J.L., D.-Y.B., and Y.-S.S.; funding acquisition, G.-A.L., G.-T.C., and J.-W.C.; investigation, D.-Y.B. and G.-A.L.; methodology, Y.-S.S.; project administration, J.-W.C. and D.Y.H.; resources, G.-T.C. J.-R.L., and K.-H.M.; writing-original draft, K.J.L.; writing - review and editing, D.Y.H. All authors have read and agreed to the published version of the manuscript.

Funding: This study was carried out with the support of the "Research Program for Agricultural Science \& Technology Development (Project No. PJ010883)". It was also supported by the 2017 Postdoctoral Fellowship Program of the National Institute of Agricultural Sciences funded by the Rural Development Administration, Republic of Korea.

Conflicts of Interest: The authors declare no conflict of interest.

\section{References}

1. Kim, H.G.; Kim, G.W.; Oh, H.; Yoo, S.Y.; Kim, Y.O.; Oh, M.S. Influence of roasting on the antioxidant activity of small black soybean (Glycine max L. Merrill). LWT Food Sci. Technol. 2011, 44, 992-998. [CrossRef]

2. Kim, M.-J.; Kim, K.-S. Functional and Chemical Composition of Hwanggumkong, Yakong and Huktae. Korean Soc. Food Cook. Sci. 2005, 21, 844-849.

3. Diaz-Batalla, L.; Widholm, J.M.; Fahey, G.C., Jr.; Castano-Tostado, E.; Paredes-Lopez, O. Chemical components with health implications in wild and cultivated Mexican common bean seeds (Phaseolus vulgaris L.). J. Agric. Food Chem. 2006, 54, 2045-2052. [CrossRef] [PubMed]

4. Bellaloui, N. Soybean Seed Phenol, Lignin, and Isoflavones and Sugars Composition Altered by Foliar Boron Application in Soybean under Water Stress. Food Nutr. Sci. 2012, 3, 579-590. [CrossRef]

5. Song, J.; Liu, Z.; Hong, H.; Ma, Y.; Tian, L.; Li, X.; Li, Y.-H.; Guan, R.; Guo, Y.; Qiu, L.-J. Identification and Validation of Loci Governing Seed Coat Color by Combining Association Mapping and Bulk Segregation Analysis in Soybean. PLoS ONE 2016, 11, e0159064. [CrossRef] [PubMed]

6. Xu, B.; Chang, S.K. Antioxidant capacity of seed coat, dehulled bean, and whole black soybeans in relation to their distributions of total phenolics, phenolic acids, anthocyanins, and isoflavones. J. Agric. Food Chem. 2008, 56, 8365-8373. [CrossRef] [PubMed]

7. Correa, C.R.; Li, L.; Aldini, G.; Carini, M.; Oliver Chen, C.Y.; Chun, H.-K.; Cho, S.-M.; Park, K.-M.; Russell, R.M.; Blumberg, J.B.; et al. Composition and stability of phytochemicals in five varieties of black soybeans (Glycine max). Food Chem. 2010, 123, 1176-1184. [CrossRef] 
8. Dajanta, K.; Apichartsrangkoon, A.; Chukeatirote, E. Antioxidant Properties and Total Phenolics of Thua Nao (a Thai Fermented Soybean) as Affected by Bacillus-fermentation. J. Microb. Biochem. Technol. 2011, 3, 56-59. [CrossRef]

9. Xiao, J.; Bai, W. Bioactive phytochemicals. Crit. Rev. Food Sci. Nutr. 2019, 59, 827-829. [CrossRef]

10. Xiao, J.B. Dietary flavonoid aglycones and their glycosides: Which show better biological significance? Crit Rev. Food Sci. Nutr. 2007, 57, 1874-1905. [CrossRef]

11. Zhao, C.; Yang, C.F.; Liu, B.; Lin, L.; Sarker, S.D.; Nahar, L.; Yu, H.; Cao, H.; Xiao, J. Bioactive compounds from marine macroalgae and their hypoglycemic benefits. Trends Food Sci. Technol. 2018, 72, 1-12. [CrossRef]

12. Gololo, S.S. Potential Adverse Effects of Alteration of Phytochemical Accumulation in Fruits and Vegetables; IntechOpen: London, UK, 2018.

13. Willcox, J.K.; Ash, S.L.; Catignani, G.L. Antioxidants and prevention of chronic disease. Crit. Rev. Food Sci. Nutr. 2004, 44, 275-295. [CrossRef] [PubMed]

14. Mossi, A.J.; Cansian, R.L.; Carvalho, A.Z.; Dariva, C.; Oliveira, J.V.; Mazutti, M.; Filho, I.N.; Echeverrigaray, S. Extraction and characterization of volatile compounds in Maytenus ilicifolia, using high-pressure CO2. Fitoterapia 2004, 75, 168-178. [CrossRef] [PubMed]

15. Nordberg, J.; Arner, E.S. Reactive oxygen species, antioxidants, and the mammalian thioredoxin system. Free Radic. Biol. Med. 2001, 31, 1287-1312. [CrossRef]

16. Ajila, C.M.; Prasada Rao, U.J. Protection against hydrogen peroxide induced oxidative damage in rat erythrocytes by Mangifera indica L. peel extract. Food Chem. Toxicol. 2008, 46, 303-309. [CrossRef]

17. Cho, G.-T.; Lee, J.; Moon, J.-K.; Yoon, M.-S.; Baek, H.-J.; Kang, J.-H.; Kim, T.-S.; Paek, N.-C. Genetic Diversity and Population Structure of Korean Soybean Landrace (Glycine max (L.) Merr.). J. Crop. Sci. Biotechnol. 2008, 11, 83-90.

18. Lee, C.; Choi, M.-S.; Kim, H.-T.; Yun, H.-T.; Lee, B.; Chung, Y.-S.; Kim, R.W.; Choi, H.-K. Soybean [Glycine max (L.) Merrill]: Importance as A Crop and Pedigree Reconstruction of Korean Varieties. Plant Breed. Biotechnol. 2015, 3, 179-196. [CrossRef]

19. Lee, Y.H. Uses of Korean landrace soybean. Bull. Korean Acad. Nativ. Species 2003, 8, 15-36.

20. Villa, T.C.C.; Maxted, N.; Scholten, M.; Ford-Lloyd, B. Defining and identifying crop landraces. Plant Genet. Resour. 2005, 3, 373-384. [CrossRef]

21. Dwivedi, S.L.; Ceccarelli, S.; Blair, M.W.; Upadhyaya, H.D.; Are, A.K.; Ortiz, R. Landrace germplasm for improving yield and abiotic stress adaptation. Trends Plant Sci. 2016, 21, 31-42. [CrossRef]

22. Lee, K.J.; Lee, J.-R.; Ma, K.-H.; Cho, Y.-H.; Lee, G.-A.; Chung, J.-W. Anthocyanin and Isoflavone Contents in Korean Black Soybean Landraces and their Antioxidant Activities. Plant Breed. Biotechnol. 2016, 4, 441-452. [CrossRef]

23. Sun, T.; Tanumihardjo, S.A. An integrated approach to evaluate food antioxidant capacity. J. Food Sci. 2007, 72, R159-R165. [CrossRef]

24. R Statistical Software. Available online: http://www.r-project.org (accessed on 3 March 2020).

25. Hammer, O.; Harper, D.A.T.; Ryan, P.D. PAST: Paleontological statistics software package for education and data analysis. Paleontol. Electron. 2001, 4,1-9.

26. Hoisington, D.; Khairallah, M.; Reeves, T.; Ribaut, J.-M.; Skovmand, B.; Taba, S.; Warburton, M. Plant genetic resources: What can they contribute toward increased crop productivity? Proc. Natl. Acad. Sci. USA 1999, 96, 5937-5943. [CrossRef] [PubMed]

27. Sthapit, B.R.; Rao, V.R. Consolidating Community's Role in Local Crop Development by Promoting Farmer innovation to Maximize the Use of Local Crop Diversity for the Well-Being of People; International Society for Horticultural Science (ISHS): Leuven, Belgium, 2009; pp. 669-676.

28. Allard, R.W. Genetic basis of the evolution of adaptedness in plants. Euphytica 1996, 92, 1-11. [CrossRef]

29. Frankel, O.H.; Brown, A.H.D.; Burdon, J.J. The Conservation of Plant Biodiversity; Cambridge University Press: Cambridge, UK, 1995.

30. Dudonne, S.; Vitrac, X.; Coutiere, P.; Woillez, M.; Merillon, J.M. Comparative study of antioxidant properties and total phenolic content of 30 plant extracts of industrial interest using DPPH, ABTS, FRAP, SOD, and ORAC assays. J. Agric. Food Chem. 2009, 57, 1768-1774. [CrossRef]

31. Phommalath, S.; Teraishi, M.; Yoshikawa, T.; Saito, H.; Tsukiyama, T.; Nakazaki, T.; Tanisaka, T.; Okumoto, Y. Wide genetic variation in phenolic compound content of seed coats among black soybean cultivars. Breed. Sci. 2014, 64, 409-415. [CrossRef] [PubMed] 
32. Tsukamoto, C.; Shimada, S.; Igita, K.; Kudou, S.; Kokubun, M.; Okubo, K.; Kitamura, K. Factors Affecting Isoflavone Content in Soybean Seeds: Changes in Isoflavones, Saponins, and Composition of Fatty Acids at Different Temperatures during Seed Development. J. Agric. Food Chem. 1995, 43, 1184-1192. [CrossRef]

33. Yamane, T.; Jeong, S.T.; Goto-Yamamoto, N.; Koshita, Y.; Kobayashi, S. Effects of Temperature on Anthocyanin Biosynthesis in Grape Berry Skins. Am. J. Enol. Vitic. 2006, 57, 54-59.

34. Cohen, S.D.; Tarara, J.M.; Kennedy, J.A. Assessing the impact of temperature on grape phenolic metabolism. Anal. Chim. Acta 2008, 621, 57-67. [CrossRef]

35. KMA. Available online: http://www.kma.go.kr (accessed on 28 January 2020).

36. Kim, J.A.; Jung, W.S.; Chun, S.C.; Yu, C.Y.; Ma, K.H.; Gwag, J.G.; Chung, I.M. A correlation between the level of phenolic compounds and the antioxidant capacity in cooked-with-rice and vegetable soybean (Glycine max L.) varieties. Eur. Food Res. Technol. 2006, 224, 259-270. [CrossRef]

37. Cho, K.M.; Ha, T.J.; Lee, Y.B.; Seo, W.D.; Kim, J.Y.; Ryu, H.W.; Jeong, S.H.; Kang, Y.M.; Lee, J.H. Soluble phenolics and antioxidant properties of soybean (Glycine max L.) cultivars with varying seed coat colours. J. Funct. Foods 2013, 5, 1065-1076. [CrossRef]

38. Moharram, A.H.; Youssef, M.M. Methods for Determining the Antioxidant Activity: A Review. Alex J. Food Sci. Technol. 2014, 11, 31-42.

39. Singh, S.; Singh, R.P. In Vitro Methods of Assay of Antioxidants: An Overview. Food Rev. Int. 2008, 24, 392-415. [CrossRef]

40. Todd, J.J.; Vodkin, L.O. Pigmented soybean (Glycine max) seed coats accumulate proanthocyanidins during development. Plant Physiol. 1993, 102, 663-670. [CrossRef] [PubMed]

41. Ramarathnam, N.; Osawa, T.; Namiki, M.; Kawakishi, S. Chemical studies on novel rice hull antioxidants. 2. Identification of isovitexin, a C-glycosyl flavonoid. J. Agric. Food Chem. 1989, 37, 316-319. [CrossRef]

42. Zhang, R.F.; Zhang, F.X.; Zhang, M.W.; Wei, Z.C.; Yang, C.Y.; Zhang, Y.; Tang, X.J.; Deng, Y.Y.; Chi, J.W. Phenolic Composition and Antioxidant Activity in Seed Coats of 60 Chinese Black Soybean (Glycine max L. Merr.) Varieties. J. Agric. Food Chem. 2011, 59, 5935-5944. [CrossRef]

43. Lee, L.-S.; Choi, E.-J.; Kim, C.-H.; Kim, Y.-B.; Kum, J.-S.; Park, J.-D. Quality Characteristics and Antioxidant Properties of Black and Yellow Soybeans. Korean J. Food Sci. Technol. 2014, 46, 757-761. [CrossRef]

44. Upadhyaya, H.D.; Reddy, K.N.; Gowda, C.L.L.; Singh, S. Identification and evaluation of vegetable type pigeonpea (Cajanus cajan (L.) Millsp.) in the world germplasm collection at ICRISAT genebank. Plant Genet. Resour. 2010, 8, 162-170. [CrossRef]

45. Ferguson, A.R. The need for characterisation and evaluation of germplasm: Kiwifruit as an example. Euphytica 2007, 154, 371-382. [CrossRef]

46. Van Treuren, R.; Van Hintum, T.J.L. Marker-Assisted Reduction of Redundancy in Germplasm Collections: Genetic and Economics Aspects; International Society for Horticultural Science (ISHS): Leuven, Belgium, 2004; pp. 139-149.

(C) 2020 by the authors. Licensee MDPI, Basel, Switzerland. This article is an open access article distributed under the terms and conditions of the Creative Commons Attribution (CC BY) license (http://creativecommons.org/licenses/by/4.0/). 